\title{
REGIÓN DE LETRAS: DESARROLLO DE LA INDUSTRIA EDITORIAL DE PASTO \\ EN EL SIGLO XIX
}

\author{
TYPE REGION: DEVELOPMENT OF THE PUBLISHING \\ INDUSTRY IN PASTO \\ IN 19TH CENTURY
}
LETRAS REGIÃO. DESENVOLVIMENTO DA INDÚSTRIA EDITORIAL NO SÉCULO XIX EM PASTO

\section{PLAZAS_Hugo Alonso, CASTELLANOS_Jennyfer Alejandra}

Magister en Diseño, Universidad de Palermo; Diseñador Gráfico Universidad Nacional de Colombia. Docente Departamento de Diseño, Universidad de Nariño. Email: hugoalonsoplazas@udenar.edu.co, Colombia.

Diseñadora Gráfica, Universidad de Nariño. Docente Departamento de Diseño, Universidad de Nariño. Email: alejacastellanosn@gmail.com, Colombia

Recibido: 21 de junio de 2017 Aprobación definitiva: 8 de mayo de 2018

DOI: http://dx.doi.org/10.22267/rtend.181901.89i

\section{RESUMEN}

El presente artículo analiza el desarrollo de la industria editorial en la Provincia de Pasto de 1837 a 1900 a partir de los emprendimientos de la época. Para abordar esta problemática se hace un recuento histórico de las imprentas que existieron en esta época, las personas vinculadas y las diferentes filiaciones con instituciones, ideologías y movimientos. De la misma forma se presentan varios aspectos relacionados con la comercialización y consumo de productos editoriales rescatados a partir de fuentes primarias de archivo. Lo anterior a través de los marcos económico, político y social presentes en el país en el siglo XIX. Al 
final se discute la constitución de una incipiente organización industrial con un enfoque cultural, no solo por el tipo de productos, sino por la incidencia en la formación de la sociedad regional del siglo XIX.

Palabras clave: Imprenta, industria editorial, comercio editorial, industria cultural.

JEL: N16, N96, O33, R11, Z10.

\section{ABSTRACT}

This article analyzes the development of the publishing industry in the district of Pasto from 1837 to 1900 . The study shows the historical recount of the founded letterpresses, workers and the filiation of them with social institutions, ideologies and movements that defined their historical situation. In the same way, it displays evidence from the records about trade and consumption of publishing. This study runs through the economic, politic and cultural frameworks in order to recognize the historic periods in the country in 19th century. Finally, it is discussed the constitution of a incipient cultural-oriented industry, not only since the cultural products like books or newspapers that were made, but also for the impact on the formation of the 19th century regional society.

Keywords: Letterpress, publishing industry, publishing trade, cultural industry.

JEL: N16, N96, O33, R11, Z10.

\section{RESUMO}

Este artigo analisa o desenvolvimento da indústria editorial na província de Pasto no período 1837-1900. Para abordar esta questão é um relato histórico da impressão que existia neste momento, pessoas ligadas a estes e as várias afiliações com instituições, ideologias e movimentos. Da mesma forma se apresentam vários aspectos com a comercialização e consumo de produtos editoriais resgatado por parte das fontes de arquivo primárias. Este através do contexto econômica, política e social vivido no país no século XIX. Finalmente, é discutido o estabelecimento de uma organização industrial incipiente com uma 
abordagem cultural, não apenas pelo tipo de produtos, mas para participar na formação da sociedade regional do século XIX.

Palavras chave: Imprensa, indústria editorial, comércio de publicação, indústria cultural.

JEL: N16, N96, O33, R11, Z10.

\section{INTRODUCCIÓN}

Entre las condiciones materiales para el desarrollo económico y social de una región se cuenta el grado de apropiación y generación de conocimiento escrito, no solo como indicador del avance científico y educativo, sino también como evidencia de la sinergia enfocada al bien común. En este sentido, se debe considerar el sistema industrial que permite la creación de los escritos, sean estos de tipo científico, periodístico, artístico, de opinión o de difusión, en cuyo eje central se encuentra la industria editorial. Esta industria se define desde sus capacidades y actualizaciones tecnológicas, desde la consolidación de un mercado de consumo como reflejo de apropiación social del producto escrito, la lectura y la difusión del conocimiento y desde su propio recorrido histórico a través de las múltiples adaptaciones a las condiciones sociales del contexto. Este artículo se aproxima a este último aspecto con la idea de responder de la forma más completa posible a la pregunta acerca de la consolidación de la industria editorial pastusa a lo largo del siglo XIX.

La historia económica colombiana muestra que el periodo comprendido entre 1824, época de la independencia, y 1920 se corresponde con la etapa de preparación de las condiciones para la transición de una sociedad tradicional a una sociedad moderna industrial, cuya aparición se concreta en 1930 (cfr. Ocampo, 1984; Kalmanovitz, 1988; Melo 1992). A pesar que las élites criollas quellevaron a cabo el proceso de independencia se expresaron de forma unánime a favor de la adopción de una modernidad al estilo de la sociedad inglesa — definida por la democracia liberal y el capitalismo económico- estas no lograron consolidar este propósito a lo largo del siglo XIX debido a un número considerable de problemas estructurales y coyunturales presentes en el país. La fragmentación geográfica y cultural, 
la debilidad del estado para imponer un modelo económico y social, el fuerte liderazgo de los caudillos regionales, la insistente participación de la iglesia en las decisiones del Estado, la dependencia de la producción agrícola y la falta de respuesta a los vaivenes del mercado externo, entre otras varias problemáticas definieron los casi cien años previos al inicio del desarrollo industrial en Colombia.

A pesar de la claridad de la explicación histórica, se hace manifiesta la necesidad de revisar dos aspectos supuestamente marginales: por un lado, el desarrollo económico de la industria editorial a lo largo del siglo XIX y por otro, la idea de que los territorios periféricos como la región de Pasto superaron el estado pre industrial solo después de la mitad del siglo XX.

Sobre el primer aspecto cabe mencionar que la producción editorial desde la invención de la imprenta estuvo adherida al pensamiento moderno llegando a ser, incluso, una de sus influencias más fuertes (cfr. Eisenstein, 2010). La producción editorial se instituyó en el país como industria desde finales del siglo XVIII y en Bogotá alcanzó un desarrollo importante a mediados del siglo XIX, tal como lo demuestra Loaiza (1999). Para 1850 casi todas la ciudades del país contaban con al menos un taller de impresión y hasta la década del 80 se multiplicaron en número y capacidad productiva promovidas por la disminución de aranceles de importación, la libertad de prensa, el auge económico de las regiones exportadoras y la confrontación política entre partidos que iniciaba en los periódicos y terminaba en los campos de batalla (Higuera, 1970). El tipógrafo Abraham Gardeazábal (1934) señalaba en sus memorias cómo se producía en Bogotá en las últimas tres décadas del siglo XIX con técnicas avanzadas, maquinaria movida a vapor, una división del trabajo definida y la administración racional de tiempos y procesos.

En cuanto a la industria pastusa Valencia (1988) describe que la mayor parte de la economía se concentró en la producción agrícola y en cierta medida en la artesanía; no obstante, según Verdugo (1988), existieron pequeñas empresas de harinas, cerveza y cerámica que surgieron en su mayoría en la última década del siglo XIX. Estas empresas alcanzaron parcialmente el estadio industrial pues si bien recurrían a técnicas y maquinaria importada, en algunos casos a vapor, dependían de los 
recursos naturales y en especial tenían formas de producción centradas en las relaciones familiares junto a bajos niveles de especialización técnica y división del trabajo. Por lo tanto, la manufactura de finales del siglo XIX mezcló elementos industriales con tradiciones artesanales para otorgar viabilidad a las empresas modernas.

Estas dos aclaraciones permiten introducir el análisis sobre la industria editorial desde una doble perspectiva, primero como una historia regional que no solo da cuenta de su desarrollo desde el relato nacional sino que toma en cuenta los factores locales como agentes de transformación y, segundo, desde la concepción cultural pues se centra en agentes sociales como artesanos e impresores y objetos culturales como libros, periódicos y hojas sueltas; ambos casos distantes del poder político.

\subsection{Contexto político y económico regional en el siglo XIX}

La independencia impulsó la instalación de imprentas en las principales capitales del país en las primeras décadas de siglo XIX, sin embargo, Pasto fue la excepción debido a su resistencia a adherirse a la nueva república. La industria editorial local inició hasta 1837 debido a la devastación económica que quedó luego de la independencia la cual impidió acumular los recursos necesarios para asumir el riesgo empresarial, pero también por las dificultades de sortear los caminos para el traslado de maquinaria, la espera para la aparición de una nueva generación de ciudadanos adictos a los ideales de la república y la constitución de una base de lectores suficiente para lograr la viabilidad de algún proyecto editorial. En este sentido, la tardía aparición de la imprenta se encuadra en las secuelas del proceso de independencia, incluso los actores que se sirvieron de la primera imprenta fueron los próceres que mantuvieron por largos periodos una fuerte influencia en la ciudad como José María Obando y Tomás Cipriano de Mosquera, entre otros; quienes además eran grandes terratenientes del Cauca.

A mediados del siglo la industria editorial se vio influenciada por los movimientos liberales que, según Álvaro Tirado (1971), ocurrieron en todo el país debido a la coalición de burgueses, artesanos y minifundistas en contra de los terratenientes. Las reformas liberales pretendieron 
desmontar los gremios artesanales tradicionales de Pasto, sin embargo, estos siguieron existiendo debido a la parcial influencia que dichas reformas llegaron a tener en el sur el país. Es así que algunos talleres de impresión mantuvieron algunas características del trabajo artesanal basadas en las relaciones familiares, la herencia del conocimiento y una mínima división del trabajo entre maestros, oficiales y aprendices. También es importante considerar que estas reformas llevaron a que la ciudad, con casi 10 mil habitantes, pasara de tener dos imprentas a mediados de la década del 50 a cinco imprentas a mediados de la década del 70 , en una escalada con no muchos paralelos en el país.

Con el establecimiento de la Regeneración y la Constitución de 1886, según Ocampo (1984), hubo un impulso ambiguo de la industria pues se aplicó el proteccionismo del sector manufacturero a través de aranceles así como se estimuló la importación de maquinaria y materias primas; no obstante el desorden del sistema bancario y los conflictos políticos crearon un ambiente conflictivo para las iniciativas empresariales que implicó un estancamiento de la economía hasta principios del siglo XX. Esto implicó en lo local que el crecimiento del número de las empresas editoriales se detuviera hasta 1899, aunque los talleres existentes se mantuvieron ocupados continuamente durante ese periodo.

\subsection{Contexto social regional en el siglo XIX}

Los aspectos sociales que mayor influencia tuvieron en el desarrollo de la industria editorial pastusa fueron los bajos niveles de alfabetismo, las dificultades de tránsito en los caminos y la polaridad política que enfilaba todos los recursos materiales, humanos y espirituales a favor de las confrontaciones bélicas.

Del alfabetismo se puede mencionar que con la instalación de las primeras escuelas públicas y del Colegio San Agustín en la década del 20 se inició un movimiento favorable para el consumo de productos editoriales, no obstante las continuas redadas de reclutamiento de jóvenes para servir a las guerras civiles sumadas a las exigencias del trabajo agrícola impactaron en la deserción estudiantil. En la última mitad del siglo los cupos educativos incrementaron progresivamente con las 
reformas liberales y la instalación de escuelas públicas, privadas y de la iglesia católica. Un informe estadístico de $1894^{1}$ señala que había 3526 estudiantes de una población calculada en 35 mil habitantes. Así mismo, la promoción de la lectura se dio por medio de la lectura dirigida en sociedades civiles como la Democrática, la Católica, la de San Vicente de Paul, entre otras que proliferaron en todo el periodo como instituciones de base ideológica y perfil político (Muñoz, 2008).

El desarrollo de los caminos fue considerablemente lento en las provincias del sur salvo por la construcción de algunos puentes que ayudaron a salvar los pasos más difíciles del camino que comunica Popayán con Quito y Túquerres con Barbacoas. Los caminos que conducen de Pasto a Neiva y el Valle del Sibundoy nunca pasaron de ser caminos de mula conocidos por comerciantes que sacaban provecho de su destreza para cruzarlos (Uribe, 1995). Con la llegada del telégrafo, en 1888 , las noticias alcanzaron un cierto grado de primicia que permitió seguir la actualidad de otras regiones del país. Según LaRosa \& Mejía (2014) el carácter regional de la prensa solo se superó entrado el siglo $\mathrm{XX}$ debido, principalmente, al aislamiento geográfico.

En cuanto a la política se reconoce que la retórica basada en la denuncia, el reclamo y la acusación imperó a lo largo del siglo XIX matizada según las leyes de prensa de cada época. Fue habitual el uso de prácticas informativas cercanas al libelo (denigración y calumnia) y al pasquín (anónimo y de estilo satírico) para exacerbar los sentimientos del pueblo en la lectura pública de condenas a los personajes locales. De las leyes de prensa se puede mencionar tres periodos: la primera, de la independencia a 1850, cuando la libertad de prensa estaba vigilada por el Tribunal de prensa, el cual sancionaba los escritores que afectaran la honra de las personas. La segunda de 1850 a 1886; fue una época de total libertad de expresión que, contrario a su espíritu, fomentó la práctica del anónimo, el uso del seudónimo y la suplantación. La tercera se estableció con las leyes regeneradoras de 1888, 1896 y 1898 que hicieron responsable al editor y al impresor de las agresiones a las autoridades civiles, militares y eclesiásticas de impugnar las decisiones

1. Informe del Prefecto de la Provincia de Pasto al Gobernador del Cauca sobre la instrucción pública. Biblioteca Universidad de Antioquía (en adelante BUdeA) El Bien Público, Enero 20 de 1894, No. 4, 13r-16v: 15. 
de las instituciones del Estado y falsear cualquier información oficial. En la práctica estas leyes acallaron a los periodistas opositores y avivaron a los oficialistas.

\section{IMPRENTAS DE PASTO EN EL SIGLO XIX}

A continuación se presentan los talleres de impresión instalados en Pasto a lo largo del siglo XIX y que se consideran como los emprendimientos editoriales que sirvieron de soporte para la posterior consolidación de la industria.

\subsection{Imprenta de Enríquez}

La primera imprenta de Pasto fue construida ex profeso gracias a la iniciativa del Comandante militar de la ciudad Teniente Coronel Antonio Mariano Álvarez y la destreza de tres artesanos locales: Pastor Enríquez, Alejandro Gálvez y Juan María Cano. La prensa fue construida con insumos y herramientas locales y los tipos fueron cortados y fundidos por el propio Enríquez. Uno de los primeros proyectos editoriales fue el periódico El Volcán editado por el médico Domingo Miño. El Volcán se imprimió en una sola hoja de tamaño octavo por las dos caras y tuvo una tirada de 100 ejemplares que entregaba semanalmente, aunque con no mucha precisión, a sus fieles suscriptores.

En los primeros años el impresor encargado fue Rafael Torres quien repartía su trabajo entre una botica de la calle real y la imprenta. Los demás artesanos se encargaban de la fundición de tipos, el tallado de letras decorativas y viñetas, el ajuste de la máquina, la preparación de la tinta, entre otras tareas especializadas. Las referencias indican que Torres trabajó hasta 1840, época en la que se dio el desenlace de la Guerra de los Supremos en contra del General José María Obando y sus seguidores, entre ellos el Coronel Álvarez. Sin propietario la imprenta pasó a manos de los artesanos que trabajaban en ella, aunque al cabo de un tiempo la responsabilidad recayó en Pastor Enríquez. Los impresos de 1850 ya muestran en su pie de imprenta la denominación Imprenta de Pastor Enríquez, la cual cambió a Imprenta Imparcial de Enríquez hacia 1856 a causa de la coyuntura política. 
La imprenta de Enríquez, como se la recordó de ahí en adelante, funcionó hasta 1875. Según Sergio Elías Ortiz (1985) la imprenta estuvo siempre recargada de trabajos incluso cuando llegó la competencia de Cito Ponce y la imprenta del Colegió Provincial (antes San Agustín y luego Académico). En la imprenta también trabajó construyendo los tipos Rosa Gálvez, esposa de Enríquez, lo que demuestra que la organización del trabajo al interior del taller se fundamentó en la familia al tenor de la costumbre artesanal.

La precariedad técnica de los primeros años se superó con el paso del tiempo y el intercambio con impresores de otras ciudades; es el caso de las recomendaciones que hizo Antonio Figueroa, impresor de la Universidad del Cauca, en cuanto al uso de un componedor y las regletas para mejorar el aspecto de las páginas (Gustavo Arboleda citado por Pérez, 1998). También se puede contar la incorporación de Pedro Rosero como impresor a partir de 1852 debido, seguramente, a que Enríquez asumió un papel de gestión que le permitiría responder por los compromisos políticos y comerciales. Más adelante, en 1857, según Alejandro Santander (1896) Enríquez adquirió una prensa importada para enfrentar la fuerte competencia impuesta por la imprenta del Colegio

La última impresión conocida fue el libro Ocios Poéticos de Benjamín Gálvez de 1875. La vida de la imprenta de Enríquez culminó casi cuatro décadas después de entregar por medios artesanales, tanto en lo técnico como en la organización productiva, un emprendimiento de carácter moderno para la ciudad. De la imprenta se sabe que la prensa importada terminó en el taller de los hermanos Santander y la de "palo", según Próspero Pereira Gamba (1896), se intentó presentar en una Exposición Industrial en Bogotá, sin embargo por su estado y la dificultad del camino fue imposible trasladarla.

\subsection{Imprentilla de Ponce}

La vida de esta imprenta fue bastante corta debido a que su propietario, el ecuatoriano Cito Ponce, estuvo exiliado en Pasto de 1848 a 1851. Ponce trajo consigo una pequeña prensa y completó, aparentemente, los útiles de trabajo con material adquirido a Enríquez. De esta forma se pudo establecer el taller que sirvió, por afinidades políticas, al partido 
conservador. Hay que recordar que los partidos políticos liberal y conservador se constituyeron definitivamente a finales de los 40 y por este influjo las imprentas de la ciudad tomaron bando: Enríquez con los liberales y Ponce con los conservadores. Ponce abandona la ciudad el 17 de mayo de 1851 perseguido, después de ser señalado como uno de los auxiliadores de la revuelta liderada por Julio Arboleda como reacción a la abolición de la esclavitud.

\subsection{Imprenta del Colegio Académico}

En 1856, por orden de la Cámara Provincial, la municipalidad adquirió una imprenta de formato mediano en Estados Unidos que le fue adjudicada al Colegio Provincial. La vida de esta imprenta fue muy intensa, incluso era común que aplazaran las entregas por agotamiento de papel o recarga de trabajos. La edición 29 de 1862 El Espectador muestra esta problemática:

La escasez de cajistas i de tipos i la preferente necesidad de publicar el Boletín Oficial del gobierno nos han impedido por tres semanas el cumplir nuestro compromiso con el público. Hoy reaparece el Espectador, i continuara apareciendo semanalmente mientras las ocupaciones oficiales de la imprenta así lo permitan. LL.EE. ${ }^{2}$

Dado que era la imprenta oficial se veía sometida al vaivén de los grupos políticos en el poder. Precisamente, la cita anterior señala el momento en que la imprenta fue ocupada por el presidente Leonardo Canal cuando trasladó la capital del país a Pasto para hacer frente a la revolución del General Tomás $\mathrm{C}$. de Mosquera. En esa ocasión el Colegio sirvió de anfitrión de algunos números del Boletín Oficial de la Confederación Granadina. Este servicio lo volvió a ofrecer al año siguiente, 1863, para la edición del Repertorio Oficial del gobierno del victorioso Mosquera.

La dependencia a los grupos políticos no permitió que las finanzas de la imprenta fueran saludables, como se ve en el Presupuesto de Rentas

2. Biblioteca Nacional de Colombia (en adelante BNC), El Espectador, Agosto 28 de 1862, No. 29, $127 \mathrm{r}-130 \mathrm{v}$ : 127. 
y Gastos del Colegio Académico de $1865^{3}$, donde los ingresos esperados por concepto de la imprenta fueron de $\$ 50$ pesos; esto comparado con los \$240 que recibía un catedrático o los \$24 que recibía el portero, demuestra que la rentabilidad esperada era reducida. Esta situación se debía a que muchos impresos eran financiados por la municipalidad en tanto fueran afines a los intereses del gobierno. Otra consecuencia de la dependencia fue la alta rotación de personal, casi al ritmo de cambio de gobiernos y la escasa renovación de material de impresión, incluso se nota en las composiciones la presencia de un estilo de letra para titulares tallado en madera seguramente por Juan Cano. El 20 de julio de 1876 la imprenta fue destruida en una revuelta en el marco de la Guerra de los Obispos; ese día justamente salió la edición 18 del periódico EI Sur Liberal que ocasionó el ataque de los revolucionarios miembros de la Sociedad Católica para hacer la quema pública de los ejemplares del periódico.

\subsection{Imprenta de Agustín Ramírez}

Hacia 1872 se generó una disputa entre diferentes facciones partidistas acerca de los privilegios en la imprenta del Colegio lo que llevó al grupo de liberales radicales a buscar la ayuda del General Mosquera para adquirir una exclusiva. En una carta de Apolinar Mutis ${ }^{4}$ dirigida al General menciona que la imprenta del Colegio estaba bajo el control conservador a través del tesorero quien tenía a los impresores a su antojo y publicaba todo tipo de pasquines. En respuesta Agustín Ramírez, un militante del radicalismo pastuso, recibió una imprenta con todos los elementos dispuestos para iniciar labores. En un comienzo se llamó Tipografía Ramírez y se dedicó a la producción de hojas sueltas de carácter político, pastorales de la Diócesis y el periódico El Censor. Sobre la procedencia de la imprenta no hay certeza aunque los tipos utilizados presentan correspondencia con los catálogos de la casas fundidoras de Estados Unidos, lo que lleva a pensar que todo el material tiene esa procedencia.

Los primeros años fueron difíciles como lo atestigua este relato del cronista francés Eduard André de 1876:

3. Archivo Histórico de Pasto (en adelante AHP) P. H. (0-4) 2-2, 1865, caja 2, folio 2.

4. Archivo Central del Cauca (en adelante ACC) carta del 14 de noviembre de 1872, carpeta No XX, M-4, documento No. 53340. 
Me encontraron alojamiento poco más o menos decente en un antiguo convento en ruinas, una parte del cual, entonces en remodelación, contenía algunas piezas más bien presentables. Estaban ocupadas por don Agustín Ramírez que ejercía la profesión de tipógrafo, oficio poco floreciente en Pasto y por el cual había hecho sacrificios financieros que el destino había recompensado muy tacañamente. Lo conocí desesperado por el mal estado en que había recibido una remesa de tipos de Nueva York y mesándose los cabellos mientras maldecía la mala fe de los yanquis, la lentitud de la travesía, los pésimos caminos de Colombia y a "esos verdugos de los arrieros" (André: 184).

Las dificultades económicas también se debieron a la competencia entre las cinco imprentas existentes que competían en una 'guerra de la pluma' basada en tomar las imprentas como trincheras para los ataques entre liberales y conservadores. Como consecuencia, los compromisos políticos eximieron del pago de los servicios editoriales a los escritores beligerantes manteniendo en crisis permanente a los dueños de los talleres. Luego de la Guerra del 76/77, vinieron muchos cambios favorables para la ahora denominada Imprenta de Agustín Ramírez. Algunos talleres cerraron y gracias a la adquisición de maquinaria procedente del remate de estos, Ramírez logró convertir el suyo en el mejor dotado. Esta nueva situación le permitió recibir encargos de parte de la Municipalidad, los colegios, la iglesia y los dos partidos políticos. Para 1893, la imprenta editaba la mayoría de los periódicos de la región.

Gracias al inventario levantado en un decomiso de $1885^{5}$ se sabe que la imprenta estaba bien dotada y que podían trabajar de 5 a 10 personas al mismo tiempo, en el local del convento de Santo Domingo. La conformación del taller correspondió a una organización de carácter artesanal, donde estaba vinculado el núcleo familiar - la esposa, los sobrinos y varios allegados políticos - en jornadas interminables de trabajo, no existía una clara división del trabajo y la retribución dependía de la posición en la jerarquía familiar.

\subsection{Imprenta de Higinio Muñoz}

En 1874, el profesor Higinio Muñoz fue influenciado por el Obispo de Pasto Manuel Canuto Restrepo para entrar al mundo editorial con

5. A.H.P. Caja 69, libro 1, folios: 148-150. 
una pequeña prensa que le sirvió para editar algunas hojas sueltas y el periódico El Católico de 1876, de la cual también era el director. Este periódico, en sus escasas 6 ediciones, sirvió de soporte al discurso del Obispo contra las reformas liberales. Higinio Muñoz no creó escuela de impresión ni mantuvo un papel activo en el mundo editorial de la ciudad, salvo por el relativo protagonismo que alcanzó a mediados de la década del 70, sin embargo, aprovechó su imprenta como instrumento de publicidad y promoción de valores morales, patrióticos y religiosos. Para la década del 90 Muñoz aún conservaba la imprenta, como lo atestigua Santander (1896), aunque aparentemente solo cumplía encargos muy puntuales relacionados con sus intereses y convicciones.

\subsection{Imprenta de Santander hermanos}

La instalación de esta imprenta fue iniciativa de Alejandro y Camilo Santander quienes ya tenían experiencia editorial pues habían participado en el periódico literario La Primavera, de 1869; así mismo, Alejandro junto con Leónidas Puyana había fundado el periódico El Sur Liberal en 1876. En 1878, tras el regreso del exilio en Ecuador por los sucesos de la guerra Alejandro y Camilo compraron la imprenta que introdujeron desde Quito los hermanos Wenceslao y Juan Florencio Gálvez en 1876. La imprenta se destinó para retomar la edición de El Sur Liberal; precisamente en el número 36 se anuncia en un aviso titulado Para Todos: "me es grato poner en conocimiento del público que he comprado la imprenta que perteneció a los doctores Gálvez i que está a disposición de todos los que quieran ocuparla"6. También anunciaba que al poco tiempo llegarían los útiles necesarios para que la imprenta no dejara nada que desear a su clientela. Al respecto se sabe que obtuvo cajetines y enseres de la imprenta del Colegio pero esto le acarreó más adelante una disputa con la municipalidad. Para completar los faltantes los hermanos Santander adquirieron algunos útiles de la imprenta de Ramón Grijalba de Ipiales.

En la primera etapa de la imprenta se editaron periódicos como La Estrella del Sur de 1880, en la que se publicaban también edictos y decretos de la administración municipal. También se editó El Núcleo Liberal de 1884 en la cual se defendía con entusiasmo la unión del

6. BUdeA, El Sur Liberal, Octubre 8 de 1878, No. 36, 141r-144v: 143. 
partido liberal y el movimiento decimista (movimiento suprapartidista que buscaba la constitución del décimo departamento con la unión de las provincias del sur). La llegada de la Regeneración significó el distanciamiento de los hermanos Santander de la vida pública y en especial de la actividad política. En esta nueva época Alejandro se limitó a la reproducción de noticias como los periódicos Noticias de Colombia de 1888 y El Reproductor de 1890 que aprovecharon la nueva conexión telegráfica para traer noticias de actualidad del acontecer nacional.

En 1891 luego de la muerte de Camilo la imprenta tomó el nombre de Imprenta de Alejandro Santander al tiempo que el impresor Elías A. Villarreal se hizo cargo casi por completo de las labores comerciales y de producción. A diferencia de la de Ramírez, la de Santander mantuvo desde el principio una organización con trabajadores en puestos fijos y responsabilidades definidas. Las publicaciones conservan más o menos las mismas características tipográficas en cuanto a formato, estilo y composición, esto implica por un lado que tenían recursos limitados y por otro, que tenía una organización orientada a la eficacia productiva. Alejandro tuvo otra faceta menos conocida como abogado y próspero propietario de molinos que de alguna forma le habría entregado las herramientas y habilidades necesarias para entender el mundo editorial como una industria cultural y comercial, por encima de los intereses políticos y familiares.

\subsection{Imprenta del Seminario}

La llegada de la imprenta del Seminario se debe al Obispo Restrepo que ordenó, en 1876, la compra en Paris de tres prensas F.M. Weiler del sistema Liberty Machine Works accionado por vapor y pedal, acompañados de una dotación completa de tipos y enseres de tipografía, así como varias máquinas de encuadernación. El costo de la maquinaria fue de $\$ 3.000$ cubierto por las amplias colectas que recaudaba la Diócesis. La imprenta fue instalada en el Colegio Seminario para producir los pastorales del Obispo y las múltiples adhesiones al bando eclesiástico en medio de la confrontación militar. A partir del 1877, luego del destierro del Obispo, la imprenta se dedicó con exclusividad a las ediciones religiosas y muy eventualmente a publicar exclamaciones de apoyo al Obispo. 
En 1882 el nuevo Obispo, Ignacio León Velazco, se encargó de organizar la Diócesis con los importantes recursos legados por la administración anterior. En este nuevo periodo, los trabajos mantuvieron distancia con el debate político a pesar que pocos años más adelante, con la Regeneración, el panorama fue mucho más ventajoso para la iglesia. A mediados de 1889 renunció el Obispo Velazco por cuestiones de salud y se aprovechó para renombrar la imprenta como Imprenta de la Diócesis. Una vez que llegó el Obispo Manuel J. de Cayzedo, en 1892, la imprenta emprende la publicación de pastorales y documentos de polémica y confrontación contra el partido liberal.

En 1896 Cayzedo se traslada a la Diócesis de Popayán y es reemplazado por Fray Ezequiel Moreno Díaz, un vehemente defensor de la doctrina radical católica y fuerte contrincante del liberalismo. El nuevo Obispo alquiló, a inicios de 1897, la imprenta a los exiliados ecuatorianos Aparicio Rivadeneira, Clemente Ponce y los hermanos Daste quienes le dan el nombre de Imprenta de N. Clemente Ponce. La imprenta en una etapa de un año imprime infinidad de documentos de resistencia contra el presidente liberal Eloy Alfaro del Ecuador, como los escritos del desterrado Obispo de Portoviejo, Pedro Schumacher. Al mismo tiempo se imprimieron varios de los escritos incendiarios del Obispo Moreno que sirvieron de preámbulo de la Guerra de los Mil Días. Una vez terminado el alquiler de la imprenta se instituyó, bajo la dirección de la Diócesis, la denominada Imprenta de la Verdad, a cargo de Eduardo M. Villarreal.

\subsection{Imprenta "Ramírez" de Gómez Hermanos}

Luego de la muerte de Agustín Ramírez en 1893 la imprenta de este pasó a manos de sus sobrinos los hermanos Gómez quienes la llamaron inicialmente Imprenta de Gómez hermanos. La imprenta atendió varios periódicos como El Bien Público de 1894, dedicado a promover el movimiento decimista. A final del siglo los hermanos Gómez se vieron envueltos en una nueva 'guerra de la pluma ', esta vez debido a la enconada lucha del Obispo Moreno contra el liberalismo. En una actitud defensiva y desafiante, al mismo tiempo, renombraron la imprenta como Imprenta "Ramírez" de Gómez hermanos, usando el apellido de Ramírez como bandera del liberalismo. Bajo este nombre se editó El Eco Liberal, 
publicación que funcionó como vocera del partido desde 1897 hasta que estalló la Guerra de los Mil Días en 1899.

La etapa de los hermanos Gómez es recordada porque mejoró la producción editorial con la edición de periódicos al estilo de los que se veían en Bogotá; además de participar en la Muestra Industrial de Bogotá del 20 de Julio de 1894 con una hoja llamada Mosaico Tipográfico, en lo que podría reconocerse como el primer catálogo tipográfico creado en la región. Fueron los primeros que promovieron sus servicios con avisos publicitarios como el que anunciaba que recibieron de Nueva York, "un surtido de tipos, orlas, viñetas, papel blanco, papel de colores de muy buena calidad y muchos útiles que facilitan la ejecución de cualquier trabajo"7. Hay registros que muestran que esta imprenta perduró más allá de 1930.

\subsection{Imprenta de Martínez F.}

Esta imprenta llegó a Pasto a medidos de 1899, poco antes del estallido de la Guerra de los Mil Días, proveniente de Ipiales donde funcionaba, desde Octubre de 1897, como Imprenta de Martínez F. y Valle y estuvo en funcionamiento hasta 1905. El periódico Los Andes registró de la siguiente forma la llegada de la imprenta:

Positivo servicio nos harán los accionistas que han comprado la de Martínez

y Valle; entre ellos se cuenta el Dr. Ángel Martínez Segura, D. Daniel Zarama, D. Carlos J. Guerrero y D. Ricardo Zarama. Quizá las empresas periodísticas y otras publicaciones logren alguna holgura ${ }^{8}$.

Es claro que llegó para atender la apretada agenda que no podían cumplir las demás imprentas de la ciudad en el auge del negocio editorial de finales de la década del 90.

7. BNC, El Bien Público, Marzo 31 de 1894, No 13, 49r-52v: 52.

8. BUdeA, Los Andes, Mayo 25 de 1899, No 8, 1r-4v: 3. 


\section{Comercialización de productos editoriales en Pasto en el siglo XIX}

\subsection{Venta, distribución y encargo de periódicos}

Desde que se inició la edición de periódicos pastusos hubo una muy buena acogida de parte de los suscriptores que agotaban las ediciones de periódicos como El Duende o El Católico; no obstante, eran comunes los inconvenientes con la recaudación de los pagos que comprometían el sostenimiento económico de estos emprendimientos editoriales. Por ejemplo, el periódico Las Máscaras, de 1850, en un aviso de última página ${ }^{9}$, suplica a sus agentes arreglar las cuentas y remitir el dinero una vez finalizado el primer trimestre. El periódico La Primavera que funcionó de 1869 a 1871, se quejó en su edición final de los suscriptores porque "no solo no son cumplidos en corresponder a nuestras súplicas sino que deben todavía el valor del primer trimestre" (Ortiz, 1935: 51).

En parte, el mal económico se debía a una práctica de promoción que consistía en el envío de ejemplares a agentes y suscriptores potenciales y en virtud de su aceptación estos realizaban el pago vía correo. Debido a la inseguridad del correo muchos ejemplares se extraviaron así como sus retribuciones monetarias, si es que estas eran honradas como lo rogaban insistentemente los editores. Un ejemplo de esto es el aviso de La Voz del Sur: "Señores Ajentes. Enviamos a UU. dos ejemplares del presente número de 'La Voz del Sur'. UU. se servirán avisarnos a vuelta de correo, siendo de nuestro cargo el porte, que número de ejemplares debemos enviar en adelante" 10 .

Dentro del esquema de promoción se daba por descontado la honradez del agente ya que por lo general eran personas reconocidas de la ciudad; por ejemplo, el periódico bogotano Anales de Jurisprudencia de 1896 tenía como agente en Pasto a Alejandro Santander. También hay que anotar que la problemática del pago no tuvo como causa el costo del ejemplar pues periódicos como El Duende llegaban a costar solamente medio real de 1837, El Centinela costaba en 1868 ф5 centavos y La Patria

9. Biblioteca Luis Ángel Arango (en adelante BLAA), Las Máscaras, Diciembre 5 de 1850, No. 6, $1 \mathrm{r}-4 \mathrm{v}: 4$. 10. BUdeA, La Voz del Sur, Febrero 9 de 1868, No 1, 1r-4v: 4. 
de $1899 \not 10$ centavos. Aunque estos tres ejemplos se ubican en épocas diferentes demuestran que eran productos asequibles en lo económico, incluso la suscripción trimestral era baja como en el caso de Las Máscaras $\$ 5$ reales en 1850 y La Unión Liberal ф30 centavos en 1884.

Como en otros espacios mediáticos la gratuidad también hacía parte de la cotidianidad informativa, muchos periódicos fueron financiados por los partidos políticos en vísperas de comicios, como lo demuestra Valencia (1994). En otros casos la financiación provenía del gobierno, como lo evidencia el contrato que firmó el representante de la Gobernación del Cauca con los hermanos Gómez para la impresión del periódico Recopilación Judicial de $1893^{11}$. En el contrato se especifican en detalle las características del periódico: 350 ejemplares de 8 páginas a dos columnas con frecuencia mensual de tres números. También se detallan aspectos como la tipografía y el papel y el pago de \$28 pesos por cada edición.

Puede inferirse que las ganancias esperadas por los editores de los periódicos eran mínimas, sin embargo la edición representaba ciertas ventajas sociales como el reconocimiento público de editores y redactores que a la postre serviría para obtener fines políticos y culturales. Un ejemplo de esto se observa en el caso del novelista Florentino Paz quien trató de alcanzar cierto prestigio como escritor fuera de las fronteras locales con la edición del periódico El Estudio de 1896. Con los ejemplares del periódico Paz remitía también su novela La Ciudad de Rutila. Debido a los problemas en la promoción ya mencionados, en el número cuatro ${ }^{12}$ el editor señala que se enviaron libros y periódicos a varias personas fuera de la ciudad y no había recibido, hasta ese momento, respuesta, ni agradecimiento, ni confirmación.

\subsection{Remitidos, avisos comerciales y redes comerciales}

Desde el principio los periódicos recibieron artículos remitidos por amigos como parte de las colaboraciones externas, sin embargo, desde mediados de la década del 80 empezaron a diferenciarse el correo de los lectores - usualmente seleccionados por el editor- y los artículos

11. BNC, Recopilación Judicial, Noviembre 25 de 1893, No 25, 193r-200v: 193-194.

12. Archivo de José María Trujillo (en adelante JMT), El Estudio, Mayo 1 de 1896, No. 4,1r-4v: 4. 
completos llamados remitidos; los primeros gratuitos y los segundos cobrados según la extensión.

La última década del siglo se distinguió por la formación de una estructura empresarial en torno a los periódicos, evidente por la disminución del costo de la suscripción y el aumento del precio de los avisos comerciales y remitidos. En este periodo, precisamente, se crea un periódico dedicado a los intereses de los comerciantes de la ciudad: El Semanario Comercial de 1898, el cual se dedicó, principalmente, a la publicación de avisos comerciales de los almacenes de productos traídos de fuera de la ciudad y del país.

Los avisos cumplían con dos funciones comerciales: por un lado promocionaban los productos con estrategias retóricas de tipo verbal y visual; como ejemplo se encuentra un aviso titulado "Revolución!"13 Que sirvió para anunciar espejos de diversas formas aludiendo indirectamente a los continuos movimientos revolucionarios de América Latina pero sin ninguna conexión ideológica con ellos. Lo anterior acompañado del uso de diversos niveles de lectura tipográfica. Por otro lado, los avisos también sirvieron para presionar a los deudores morosos con la exposición pública:

Por última vez. Aviso a mis clientes que no se han dignado cancelar sus cuentas del año pasado, que si hasta el próximo número de este periódico no las cancelan, publicaré sus nombres y apellidos, y los entregaré al desprecio de sus conciudadanos. Eleázaro Rodríguez ${ }^{14}$

Con la presencia de los avisos aumenta la responsabilidad editorial para el cumplimiento en tiempo y forma: "Excusa le pedimos a nuestros abonados por la demora del presente número ocasionada por haber agotado las mayúsculas en la adhesión que publicamos en alcance"15

En cuanto a las redes comerciales los periódicos pastusos alcanzaron progresivamente amplios territorios a pesar de la geografía. El Duende tuvo como representante comercial únicamente a José Vivanco de

13. BNC, Semanario Comercial, Marzo 18 de 1898, No. 1, 1r-4v: 1.

14. JMT, Semanario Comercial, Octubre 18 de 1898, No. 18, 1r-4v: 4.

15. BNC, El Bien Público, Junio 20 de 1894, No 23: 89r-92v: 92. 
Pasto, en cambio El Volcán de 1850 mostraba una distribución a 9 ciudades. Para 1868 periódicos como El Centinela exponían en su primera plana las 40 ciudades a las que llega en Colombia, Ecuador y Venezuela con el nombre de sus agentes. Y La Voz del Sur presentaba los agentes que tenía en 30 ciudades, uno de cada partido en cada destino. A partir de la década del 70 desaparece la exhibición pública de agentes y se reemplaza por saludos y felicitaciones entre periódicos de la misma línea editorial que servían para demostrar tanto las filiaciones como la lectura en otras regiones de las letras locales. Otra práctica que se desarrolló en la década del 80 fue el canje entre periódicos regionales y foráneos.

\subsection{Venta de libros y bibliotecas de la ciudad}

El comercio de libros se centró en los libros educativos y religiosos, tanto los que se producían en las imprentas locales como los traídos por los comerciantes. Esto se aprecia en una Ordenanza Municipal de $1867^{16}$ que establece la compra o reimpresión del Libro de Oro de las Escuelas del chileno José Victorino Lastarria, un texto educativo enfocado a la modernización de la enseñanza y promovido por los gobiernos liberales para la educación primaria.

En los almacenes de comercio se vendían biblias, evangelios y textos educativos como el Compendio de Gramática Castellana de Francisco Marulanda Mejía. Este libro, reza el anuncio que lo promocionaba en el periódico El Obrero ${ }^{17}$, había sido adoptado como texto de enseñanza en la Universidad Republicana y otros colegios de Colombia y se vendía en el almacén de Leovijildo Galvis a $\$ 1,20$ pesos el ejemplar. De la misma forma, las dinámicas comerciales de los almacenes requirieron tipos de libros que demostraran éxito en ventas, lo que reñía con la calidad esperada de estos. Un anuncio de EI Bien Público resalta esta situación cuando anunciaba la llegada de una nueva Gramática de la lengua castellana del rector de la Universidad del Cauca Martín Restrepo Mejía: "Al anunciar su aparición, lo hacemos convencidos de que no es un libro más, como tantos que inundan nuestras librerías, que carecen de

16. Artículo $4^{\circ}$ de la Ordenanza No 57 en el libro: BNC, Ordenanzas de la Corporación Municipal de Pasto, Marzo 28 de 1867: 6.

17. BNC, El Obrero, Enero 1 de 1890, No 6, 21r-24v: 24. 
importancia y hasta de utilidad" ${ }^{18}$. Por otra parte, sobre las librerías solo se ha confirmado la existencia de una del empresario Manuel Santiago Guerrero instalada en la década del 90 y que perduró hasta 1930; según Ignacio Rodríguez (1984) esta fue una de las mejores del país.

Otros modelos de comercialización de libros incluyeron el uso de representantes locales y el uso de avisos comerciales. En el primer caso sirve de ejemplo este aviso: "Geografía de Colombia. Por Ángel María Díaz Lemos. Obra adoptada por el Ministerio de Instrucción Pública como texto oficial para las escuelas del Gobierno. Precio 12 reales. De venta en la casa del Sr. Benigno Obregozo"19. En cuanto a los avisos resalta uno aparecido en La Unión Liberal de 1884 en el cual el editor bogotano Ignacio Borda anunciaba la reedición de El Carnero de Juan Rodríguez Freyle. El aviso anuncia la apertura de suscripciones en todas las librerías de la ciudad por $\$ 1,20$ pesos para la adquisición de la próxima edición. Al final del aviso se dirige a los editores en las siguientes palabras: "Los señores editores de periódicos que tengan a bien insertar el presente aviso, por cinco veces, recibirán en cambio un ejemplar de dicha obra"20.

Sobre el destino de los libros se sabe que en un cierto porcentaje se destinaron a las tres bibliotecas de la ciudad — la biblioteca de la Sociedad Filológica, la del Colegio Académico y la del Colegio San Felipe Neri- en calidad de donaciones. La biblioteca de la Sociedad Filológica fue una iniciativa filantrópica que organizaron los miembros de la Sociedad entre ellos los hermanos Santander, los hermanos Gálvez y otros varios que se habían reunido en torno al periódico La Primavera. La biblioteca ya recibía donaciones en 1876 las cuales eran publicadas en El Sur Liberal. Entre estas se destacan libros de gramática en varios idiomas, historia nacional y regional, libros de religión, literatura, filosofía, jurídica, medicina, entre otros.

18. BNC, El Bien Público, Noviembre 19 de 1894, No. 41, 161r-164v: 164

19. BNC, El Meridional, Enero 20 de 1890, No 10, 79r-86v: 86.

20. BUdeA, La Unión Liberal, Octubre 1 de 1884, No 11, 1r-4v: 4. 


\section{CONCLUSIONES}

En sus primeros 20 años la industria editorial pastusa fue una iniciativa soportada por organizaciones artesanales que le impregnaron las características de un oficio tradicional en aspectos como el trabajo, la producción y la comercialización. Esta situación sufrió un vuelco hacia 1856 cuando la imprenta se convirtió en una herramienta de la institucionalidad política que respondía al partido al mando. La lógica institucional se torna conflictiva ya entrada la década del 70 dando paso a la multiplicación de las imprentas privadas, ahora percibidas como instrumentos estratégicos para la confrontación política. A mediados del 70 fue importante la figura del Obispo Restrepo porque promovió la constitución de tres imprentas: la de Muñoz, la de los hermanos Gálvez y la del Seminario; y de cierta manera estuvo involucrado en la destrucción de la del Colegio Académico. Luego de la guerra del 76/77 la producción se concentró en tres imprentas bien constituidas: Ramírez, hermanos Santander y Seminario, las cuales funcionaron casi a tope hasta finalizar el siglo. Una última etapa se puede reconocer en el impulso comercial de los periódicos en el último lustro del siglo XIX que mostró una edición más profesional y responsable. Estas cuatro etapas de la producción y comercialización se pueden entender como fases progresivas del desarrollo de la industria editorial.

Por otra parte se puede reconocer que así como la imprenta fue instrumento de todo tipo de batallas también lo fue para la promoción social de varios impresores provenientes de las clases populares como Enríquez, Ramírez y los hermanos Villarreal. La estima de los impresores en la sociedad crecía según se ampliaba el peso político de estos como agentes sociales. Otros como Muñoz y Santander, reconocidos profesionales en otros campos, se mantuvieron en el mundo de la impresión como parte de su agenda en procura de defender y enaltecer los valores de la Provincia ante el resto del país.

Sobre la comercialización de productos editoriales se reconoce que se vio reducida a los círculos político, religioso y económico de la Provincia. Por el carácter inmediato y urgente de las hojas sueltas en muy contadas ocasiones alcanzaban una distancia considerable, 
a lo sumo llegaban a las provincias vecinas, por lo tanto su público e intercambio era de carácter local. Estas estaban financiadas por el autor aunque presentaban dificultades en la distribución pues la gran mayoría expresaba vindicaciones, es decir defensas a personas injustamente atacadas, que obtenían por respuesta otra hoja, en un debate público que culminaba por agotamiento económico o en medidas de fuerza fuera del mundo editorial. En el caso de los libros hubo dos prácticas comerciales complementarias, por un lado las imprentas asociadas a colegios, como el Académico y el Seminario, hicieron reimpresiones de libros educativos para atender la demanda local y por otro, hubo venta de libros traídos de otras ciudades por encargo o surtido de obras de cierto reconocimiento.

Finalmente, hay que resaltar que en general la industria editorial pastusa del siglo XIX no estuvo orientada a la obtención de plusvalía sino a la participación en la formación de la sociedad lo que la sitúa como una industria no solo de productos culturales sino cultural en sí misma. Esta industria se caracterizó por la mezcla de aspectos modernos con aspectos tradicionales para poder desenvolverse en medio de las tensiones políticas, económicas y militares que caracterizaron el periodo decimonónico de la región. 


\section{REFERENCIAS}

(1) André, É. (2013). La América Equinoccial. La región de Pasto (Cauca). En Navas Sanz, Pablo (compi.) Colombia en Le Tour de Monde. Bogotá: Villegas Editores.

(2) Eisenstein, E. (2010) La imprenta como agente de cambio. México: Fondo de Cultura Económica.

(3) Gardeazábal, A. (1934). "Memorias de un tipógrafo". En Arte Gráfica No. 12, pp. 12-18.

(4) Higuera, T (1970). La imprenta en Colombia. Bogotá: Inalpro.

(5) Kalmanovitz, S. (1988). Economía y nación. Una breve historia de Colombia. Bogotá: Tercer Mundo Editores.

(6) Larosa, M ; Mejía, G (2014). Historia concisa de Colombia (1810 - 2013). Bogotá: Pontificia Universidad Javeriana.

(7) Loaiza, G (1999). "El neogranadino y la organización de hegemonías: contribución a la historia del periodismo colombiano". En Historia Crítica No. 18 pp. 59-80.

(8) Melo, J (1992). Predecir el pasado. Ensayos de historia económica. Bogotá: Fundación Simón y Lola Guberek.

(9) Muñoz, L (2008). "Desde la sociedad reparadora: Pasto 1865, hasta la sociedad El Carácter: Ipiales 1913”. En Revista de Historia, Vol. 13, No 73, pp. 23-32.

(10) Ocampo, J (1984). Colombia y la economía mundial 1830-1910. Bogotá: Siglo Veintiuno Editores.

(11) Ortiz, S (1935). Noticia sobre la imprenta y las publicaciones del sur de Colombia durante el siglo XIX. Pasto: Imprenta del Departamento.

(12) Pereira $P$ (1895). "Sucesos de mi tiempo (de mis recuerdos íntimos de patria y familia)". En Revista Literaria, junio, entrega 50.

(13) Pérez, V (1998). "Imprenta y periodismo en Pasto durante el siglo XIX". En Manual Historia de Pasto. Vol. II, pp.62-86. 
(14) Rodríguez, I (1984). Perfiles nariñenses de antaño. Biografías de nariñenses ilustres. Pasto: Tipografía Javier.

(15) Santander, A (1896). Biografía de D. Lorenzo de Aldana y Corografía de Pasto. Pasto: Imprenta Gómez Hermanos.

(16) Tirado, A (1971). Introducción a la historia económica de Colombia. Bogotá: Universidad Nacional de Colombia.

(17) Uribe, M (1995). "Caminos de los Andes del sur: los caminos del sur del Cauca y Nariño". En Moreno de Ángel, Pilar (edit.) Caminos reales de Colombia. Bogotá: FEN, pp. 61-71.

(18) Valencia, A (1988). Estado Soberano del Cauca. Federalismo y regeneración. Bogotá: Banco de la República.

(19) Valencia, A (1994). Las luchas sociales y políticas del periodismo en el Estado Soberano del Cauca. Cali: Gobernación del Valle del Cauca.

(20) Verdugo, P (1988). "Algunas consideraciones sobre la historia de Pasto: El siglo XIX y las raíces del presente". En Yie Polo, Álvaro (compi.) Pasto 450 años de historia y cultura. Pasto: Universidad de Nariño. 